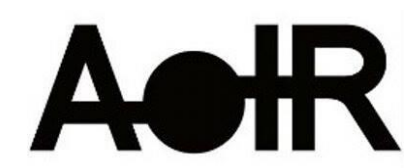

Selected Papers of \#AoIR2021:

The 22nd Annual Conference of the

Association of Internet Researchers

Virtual Event / 13-16 Oct 2021

\title{
PROMOTING SELF-HELP_HOW INTERNET USERS PROTECT THEMSELVES AGAINST ALGORITHMIC RISKS
}

\author{
Author \#1 Kiran Kappeler \\ Author \#1 University of Zurich \\ Author \#2 Noemi Festic \\ Author \#2 University of Zurich \\ Author \#3 Tanja Rüedy \\ Author \#3 University of Zurich \\ Author \#4 Michael Latzer \\ Author \#4 University of Zurich
}

\section{Prevalence of Algorithmic Risks}

In today's digitized society, internet users increasingly rely on online services that apply algorithmic selection (e.g., Google Search, Facebook News Feed). By automatically selecting information sets and assigning relevance to them, algorithms affect our daily lives in many ways. An input-throughput-output model helps to better grasp this algorithmic selection (Latzer et al., 2014): Based on input data (e.g., users' click behaviour, user requests), computational procedures (throughput) produce an output (e.g., allocated advertisements, tailored search results). This governing potential of algorithms has been associated with a variety of societal risks such as privacy breaches, surveillance, manipulation, or overuse (Larus et al., 2018; Ruckenstein \& Granroth, 2020; Syvertsen, 2020).

\section{Self-Help Strategies as a Coping Mode}

Despite increasing statutory regulation (e.g., the General Data Protection Regulation in the European Union) as a governance mode, a sense of helplessness and a wish for more control over opaque algorithms remain prevalent sentiments among internet users (Festic, 2020). We argue that self-help strategies (see Illouz, 2008 for a critical appraisal of the psychological term) such as adjusting one's privacy settings provide a complementary way for internet users to cope with algorithmic risks (see Boerman et al., 2018; Ireland, 2020).

Suggested Citation (APA): Kappeler, K., Festic, N., Rüedy, T. \& Latzer, M. (2021, October). Promoting Self-Help-How Internet Users Protect Themselves Against Algorithmic Risks. Paper presented at AolR 2021: The 22nd Annual Conference of the Association of Internet Researchers. Virtual Event: AolR.

Retrieved from http://spir.aoir.org. 


\section{Research Gap}

Currently, research into the factors that encourage internet users to apply self-help strategies against algorithmic risks mainly focuses on privacy protection. So far, studies have revealed response efficacy or internet skills as well as the perceived severity of those risks as important predictors of protection behavior (e.g., Boerman et al., 2018; Büchi et al., 2017). Empirical studies on how internet users cope with diverse algorithmic risks and what factors play together in being associated with various selfhelp strategies that rely on nation-level samples remain scarce. This article contributes to filling this gap by addressing the following research question: What factors promote internet users' self-help against the algorithmic risks surveillance, manipulation, and overuse?

\section{Theoretical Background for Coping with Risks}

According to previous empirical studies (e.g., Boerman et al., 2018; Büchi et al., 2017) and theoretical approaches like the protection motivation theory (Rogers, 1975), the health belief model (Rosenstock, 1974) and the integrated behavior model (Montano \& Kasprzyk, 2008), different factors that promote coping with risks are plausible. From this basis we derive the following three factors and hypothesize that they are positively associated with the use of self-help strategies against algorithmic risks: risk awareness (H1), negative risk-related experiences (H2), and internet skills $(H 3)$, shown in figure 1. Furthermore, on the same basis, we hypothesize that these influencing factors correlate $(H 4)$

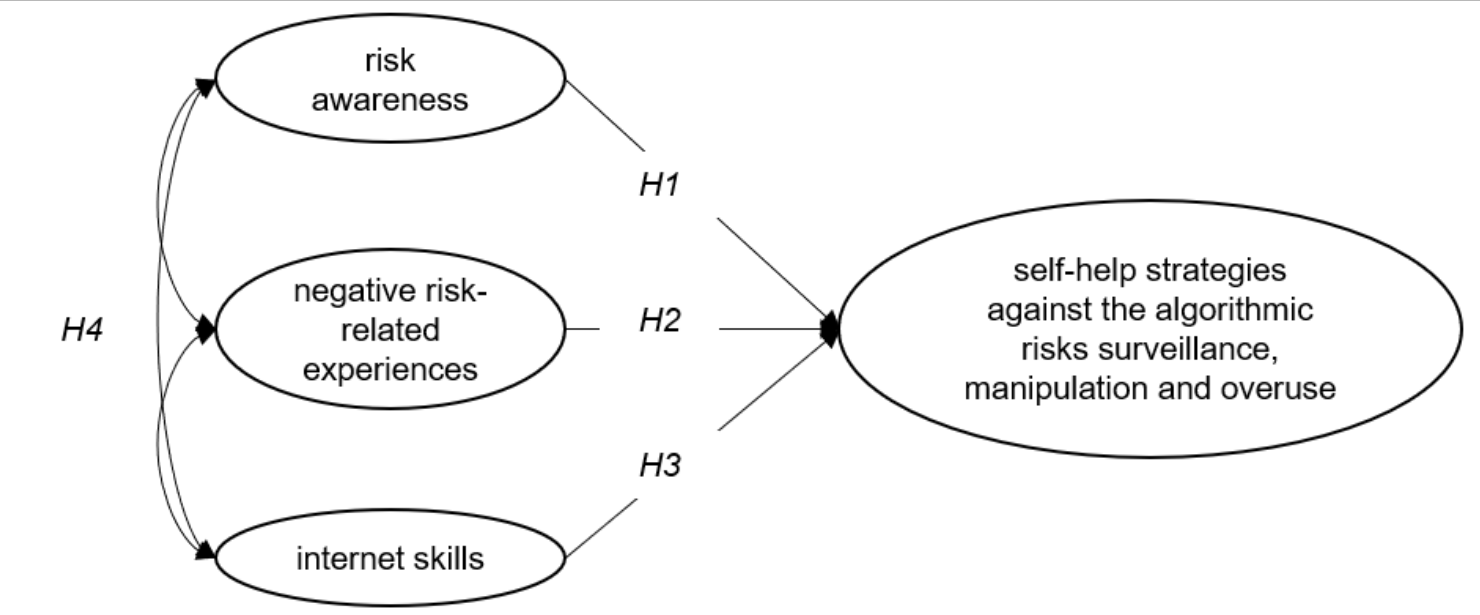

Figure 1. Model of the factors associated with internet users' use of self-help strategies against algorithmic risks.

\section{Research Design}

The data we use stems from a nationally representative survey of internet users aged 16 and over $\left(\mathrm{N}_{2018}=1,202\right)$. We calculated a separate structural equation model (SEM) for each type of risk-surveillance $(S)$, manipulation $(M)$ and overuse $(O)$-to analyze the influence of risk awareness $(H 1)$, negative experiences $(H 2)$ and internet skills $(H 3)$ on the use of self-help strategies. The concepts were measured differently across types 
of risks. Firstly, respondents were asked how often (never - often) they think about risks associated with algorithmic selection. These items include for instance the constant monitoring of internet users $(S)$, the danger of one-sided information (M) or using the internet too much $(O)$. Secondly, respondents were asked to what extent (do not agree at all - strongly agree) they have experienced negative consequences of internet use that are related to algorithmic risks. This concept was measured by items such as being surveilled $(S)$ or confronted with untrue claims $(M)$ or relying to strongly on the internet (O). Thirdly, respondents were asked to indicate their understanding (do not understand the term at all - completely understand the term) of a list of terms like 'algorithm' or 'personalized recommendation' that are related to the internet and algorithmic selection (H3) (adapted from Hargittai, 2005). The items that measure internet skills were the same for all three types of risks. Finally, we asked respondents how often (neveralways) they applied self-help strategies like for instance deleting cookies $(S)$, using an adblocker $(M)$ or consciously not using certain websites $(O)$.

\section{Results}

Figure 2 summarizes the results of the three separate SEM we calculated.

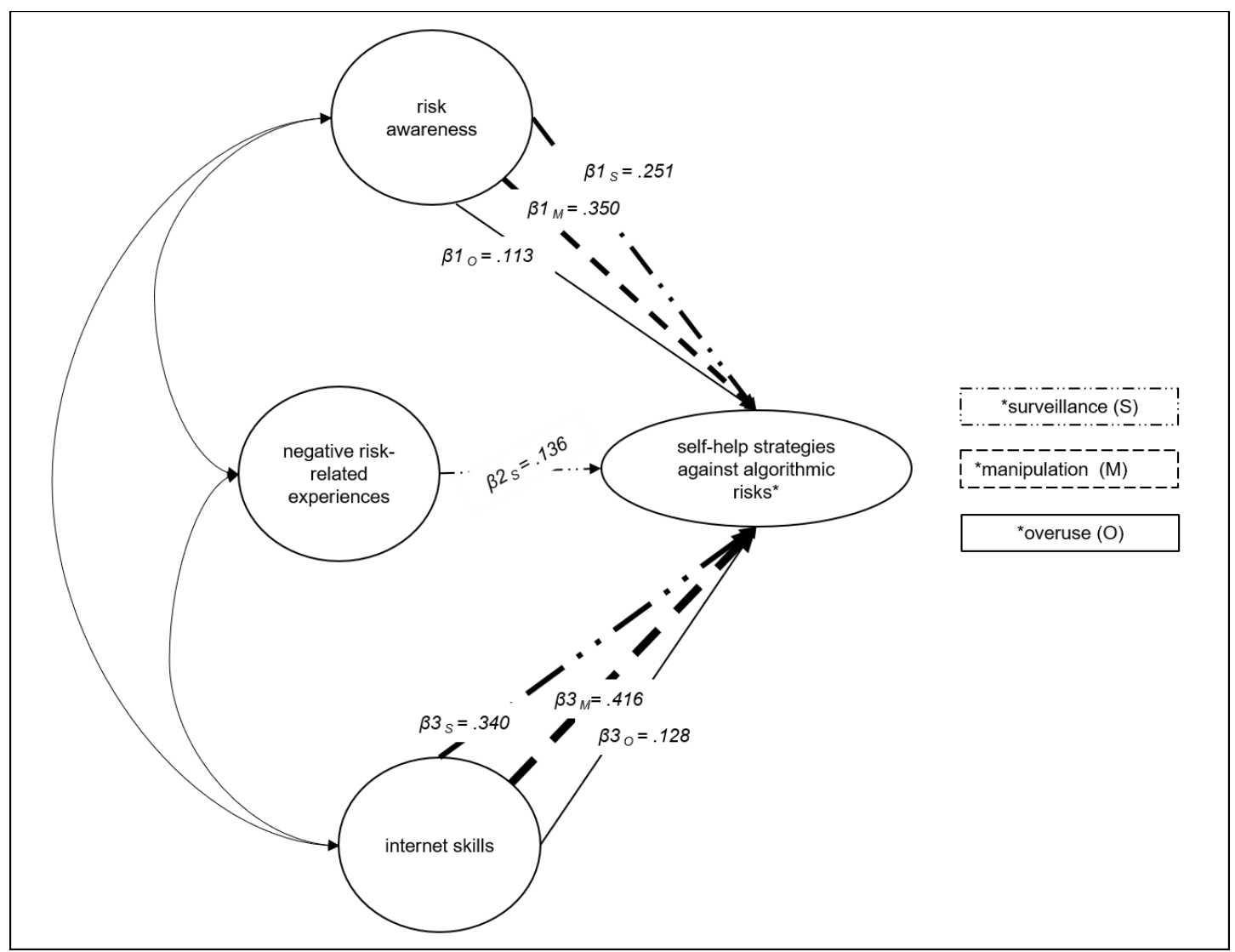

Figure 2. Summary of the three SEM for factors associated with internet users' application of self-help strategies against surveillance, manipulation, and overuse. Note: Only significant effects $(\mathrm{p}<.05)$ are depicted. Arrow width is scaled to standardized effect size. For better readability, the risk-specific items measuring the concepts (all factor loadings $>.400$ ) were not included in this figure. 
For surveillance, the fit indices of the SEM were acceptable $\left(\chi S^{2}=222.876 ; d f_{S}=59\right.$; $p<.05 ; C F I_{S}=.936 ; T L I_{s}=.915 ; R M S E A_{s}=.048 ; S R M R S=.042$ ). The results reveal that the self-help strategies against surveillance are positively associated with risk awareness, with having lived through negative risk-related experiences and with the level of internet skills. For surveillance, we can accept all our four hypotheses $\mathrm{H} 1 \mathrm{~s}, \mathrm{H} 2 \mathrm{~s}, \mathrm{H} 3 \mathrm{~s}$ and $\mathrm{H} 4 \mathrm{~s}$.

For manipulation, the fit indices of the SEM were also acceptable $\left(\chi M^{2}=165.929 ; d f_{M=48}\right.$;

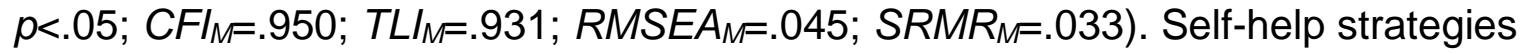
against manipulation are positively associated with risk awareness and with the level of internet skills, but not with negative experiences. For manipulation, we can thus accept $H 1_{M}$ and $H 3_{M}$, as well as $H 4_{M}$.

For overuse, the fit indices of the SEM were acceptable $\left(\chi_{o}^{2}=158.090 ; d f_{O}=39 ; p<.05\right.$; $\left.C F I_{O}=.932 ; T L I_{O}=.905 ; R M S E A_{O}=.050 ; S R M R_{O}=.038\right)$ as well. Self-help strategies against overuse are positively associated with risk awareness and with internet skills, but not with having lived through negative risk-related experiences. For overuse, only $\mathrm{H} 1 \mathrm{O}$ and $\mathrm{H}_{3} \mathrm{O}$ can be accepted. Here, only awareness of perceived overuse correlates with negative experiences.

\section{Discussion}

In sum, our findings show that awareness of algorithmic risks and the level of internet skills (and negative risk-related experiences for surveillance) are important predictors for the use of self-help strategies against algorithmic risks. By shedding light on how internet users cope with algorithmic risks such as surveillance, manipulation and overuse, this study provides valuable insights for policy makers. Awareness of algorithmic risks and internet skills should be promoted to increase internet users' selfhelp in coping with algorithmic risks. Nevertheless, it should not remain the only coping mode. Self-help cannot substitute but only complement statutory regulation and companies that apply algorithmic services should be held accountable for the risks they create.

\section{References}

Boerman, S. C., Kruikemeier, S., \& Zuiderveen Borgesius, F. J. (2018). Exploring Motivations for Online Privacy Protection Behavior: Insights From Panel Data. Communication Research, 1-25.

Büchi, M., Just, N., \& Latzer, M. (2017). Caring is not enough: The importance of Internet skills for online privacy protection. Information, Communication \& Society, 20(8), 1261-1278.

Festic, N. (2020). Same, same, but different! Qualitative evidence on how algorithmic selection applications govern different life domains. Regulation \& Governance, rego. 12333.

Hargittai, E. (2005). Survey Measures of Web-Oriented Digital Literacy: Social Science Computer Review. 
Illouz, E. (2008). Saving the Modern Soul: Therapy, Emotions, and the Culture of SelfHelp. University of California Press.

Ireland, L. (2020). Predicting Online Target Hardening Behaviors: An Extension of Routine Activity Theory for Privacy-Enhancing Technologies and Techniques. Deviant Behavior, 1-17.

Larus, J., Hankin, C., Carson, S. G., Christen, M., Crafa, S., Grau, O., Kirchner, C., Knowles, B., McGettrick, A., Tamburri, D. A., \& Werthner, H. (2018). When Computers Decide: European Recommendations on Machine-Learned Automated Decision Making. Association for Computing Machinery.

Latzer, M., Hollnbucher, K., \& Just, N. (2014). The economics of algorithmic selection on the Internet. Working Paper-Media Change \& Innovation Division. University of Zurich.

Montano, D. E., \& Kasprzyk, D. (2008). Theory of reasoned action, theory of planned behavior, and the integrated behavioral model. In Health Behavior and Health Education. Theory, Research, and Practice. Jossey-Bass.

Rogers, R. W. (1975). A Protection Motivation Theory of Fear Appeals and Attitude Change. The Journal of Psychology, 91(1), 93-114.

Rosenstock, I. M. (1974). Historical Origins of the Health Belief Model: Health Education Monographs.

Ruckenstein, M., \& Granroth, J. (2020). Algorithms, advertising and the intimacy of surveillance. Journal of Cultural Economy, 13(1), 12-24.

Syvertsen, T. (2020). Digital Detox. Emerald Publishing Limited. 